\title{
Evaluation of outreach clinics held by specialists in general practice in England
}

\author{
Matthew Bond, Ann Bowling, Alison Abery, Marie McClay, Edward Dickinson
}

\begin{abstract}
Objectives-To measure the processes of care, health benefits and costs of outreach clinics held by hospital specialists in primary care settings.

Design-The study was designed as a case-referent (comparative) study in which the features of 19 outreach clinics (cases) were compared with matched outpatient clinics (controls). The measuring instruments were self administered questionnaires. Patients were followed up at six months to reassess health status. The specialties included in the study were cardiology, ENT, general medicine, general surgery, gynaecology and rheumatology.
\end{abstract} Setting-Specialist outreach clinics in general practice in England, with matched outpatient clinic controls.

Subjects-Consecutive patient attenders in the outreach and outpatient clinics, their specialists, the outreach patients' general practitioners, practice managers and trust accountants. Patients' response rate at baseline: $78 \%(1420)$.

Main outcome measures-Patient satisfaction, doctors' attitudes, processes and health outcomes, costs.

Results-Outreach patients were more satisfied with the processes of their care than outpatients, their access to specialist care was better than that for outpatients and they were more likely to be discharged. Doctors reported that the main advantages of the outreach clinic were improved patient access to specialists and convenience for patients, in comparison with outpatients, and most GPs and specialists felt the outreach clinic was "worthwhile". At six month follow up, the health status of the outreach sample had significantly improved more than that of the outpatients on all eight sub-scales of the HSQ-12, but this was probably because of their better starting point at baseline. The impact of outreach on health outcomes was small. The NHS costs of outreach were significantly higher than outpatients. An increase in outreach clinic size would reduce cost per patient, but would lead to the loss of most of the clinics' benefits.

Conclusions-While the process of care was of higher quality in outreach than in outpatients, and the efficiency of care was also greater in the latter, the effect on patients' health outcomes was small. Responsiveness to patients' views and preferences is an essential component of good quality service provision. However, the greater cost of outreach raises the issue of whether improvements in the quality and efficiency of health care, without a substantial impact on health outcomes, is money well spent in a publicly funded health service. On the other hand, the real costs of outreach in comparison with outpatients clinics can probably only be truly estimated in a longitudinal study with a resource based costing model derived from documented patient attendances and treatment costs over time in relation to longer term outcome (for example, at a two year end point).

(F Epidemiol Community Health 2000;54:149-156)

The need to balance the supply of limited resources and increasing demands for spending on health care has led to international debates on health care provision and priorities. ${ }^{12}$ In some countries, such as the United Kingdom, with well developed primary care systems, it has also led to increasing attempts to shift the balance of care increasingly from the secondary to the primary care sector. The publicly funded NHS, with its foundations laid on the principle of equity, is popular among the British public and reflects an ethos of community responsibility, in contrast with the prevailing individualism that characterises private health care systems. ${ }^{3}$ The well developed primary care system, involving the general practitioner (GP) as gatekeeper to further services, has helped to keep health care costs down. ${ }^{4}$ Ninety per cent of health care contact takes place in primary care. Despite this, the unexplained variation in GPs' hospital referral rates, and increasing healthcare costs, has led to the search for methods of improving efficiency and effectiveness. ${ }^{45}$ Although strong primary care based health care systems may have lower costs ${ }^{6}$ the advantages of promoting this shift are not purely financial, and include the benefits of providing greater coordinated and continuous care. A later addition to the NHS reforms, which drew largely on the US literature on managed competition ${ }^{78}$ was GP fundholding (which gave GPs control of their own budgets for patient care)..$^{9-12}$ Policy makers initially envisaged that fundholding would enable GPs to counterbalance the entrenched power of hospitals and achieve higher quality and more accessible care for their patients, albeit at risk of creating inequities between practices. ${ }^{13}$ There is no good evidence that fundholding increased the shift of care from specialist to primary care services, or that referral behaviour and quality of care 
improved. ${ }^{4}{ }^{14}$ In the drive for greater efficiency, policy makers have now turned their attention to replacing GP fundholding schemes with new local commissioning schemes within Primary Care Goups, with GPs and other purchasing bodies acting in partnership. ${ }^{15}$

The boundaries between health care systems is becoming blurred with the widespread health care reforms across Europe, ${ }^{16}$ the introduction of market principles and managerialism, ${ }^{17}$ and the direction of change in Eastern Europe towards insurance based systems. ${ }^{18}$ However, international differences also exist in the extent of the coverage of populations with strong primary health care systems. ${ }^{19}$ Despite this, much can be learned from different systems about cost effective methods of organising health care, and much of Europe is observing developments in the NHS with interest.

Within the framework of the widespread development of GP fundholding schemes during the 1990s, specialist run clinics held in general practice and community health care settings (known as specialist outreach clinics) have increased rapidly across England, and numbers are reported to be large. ${ }^{20}$ The new local commissioning schemes within PCGs, ${ }^{15}$ may give further impetus for the local purchasing of specialist care in primary and community settings, given their popularity among GPs. Surveys of GPs and trusts ${ }^{20}$ have reported that the most popular outreach specialties are those with high patient volume and, in many cases, long waiting lists - for example, in rheumatology, ENT, gynaecology, general surgery, orthopaedics and dermatology.

While some specialists and trust executives have mixed feelings about the costeffectiveness of outreach services (in relation to the best use of the specialists' time), others have been keen to establish the clinics as a means of income generation, particularly in surgical specialties where patients are referred on to the trust for intervention, and in areas where there is strong competition from neighbouring trusts. ${ }^{20}$ While reviews have summarised the advantages and disadvantages of outreach from the small amount of published research, ${ }^{21-27}$ previous investigators have not reached uniform conclusions about the costs and benefits of outreach clinics in comparison with outpatients. Part of the problem has been the failure to control for the case mix effects of severity of condition and patient status (new/ follow up patient) because of relatively small sample sizes.

\section{Methods}

STUDY DESIGN

The study reported here aimed to evaluate outreach clinics held by hospital specialists (consultants) in primary care settings (GPs' surgeries), in comparison with hospital outpatients as controls. The specialties included in the study were cardiology, ENT, general medicine, general surgery, gynaecology and paediatrics, rheumatology. The study was designed as a case-referent study in which the features of the specialists' outreach clinics (cases) were compared with the same specialists (consult- ants) outpatient clinics (controls). This minimised variation between the two types of clinics that might have been attributable to the effects of different specialists conducting them.

Self administered questionnaires were given to patients in both clinic settings (health status, satisfaction, processes, costs), specialists in both clinics (individual patient clinical sheets and a questionnaire about the processes of the clinic and attitudes), GPs housing the outreach clinics (individual patient clinical sheets and a questionnaire about the processes of the clinic and attitudes), their managers, and to the accountants in the trusts holding the study outpatient clinics (on costs). Patients were followed up by mail to assess their health outcomes six months later.

Outreach clinics were sampled from a national screen of specialists, trusts and health authorities that aimed to identify them. Nineteen outreach clinics were included in the study, each with same specialist outpatient clinic controls (one of these was a duplicate covering two outreach clinics) from 14 hospital trusts. The areas included were Yorkshire, Greater Manchester, Merseyside and Lancashire, Cheshire, Nottinghamshire, Leicestershire, Suffolk, Buckinghamshire, Warwickshire, Kent, Sussex, Devon, outer London and Essex. The sample size of clinics and patients was based on the number of clinics that could be managed on a national basis, and that could satisfy calculations for statistical power with the patient and the clinic as the unit of analysis (this was based on the detection of differences of $15-20 \%$ between patient groups in the main variables of interest, at a power of $80 \%$ and significance at $5 \%$ ).

\section{MEASURES}

Costs included patients' personal costs (for example, costs of travel, carers, child minders, time); specialists' travel costs and the opportunity cost of travel time (only applicable to the outreach clinics); NHS staffing costs per clinic; patients' treatment costs (prescribed medication for the study condition, investigations and interventions, including tests procedures, treatment, surgery); NHS fixed overhead costs (building, running and maintenance costs). The measures used were those developed by Gosden $e t a l^{25}{ }^{26}$ for their evaluation of outreach clinics in dermatology and orthopaedics. As with their study, the overhead cost information was collected from managers and accountants of general practices and hospital trusts, but was excluded from the marginal costs (the additional cost to treat an extra patient) because of the wide variation in the content and quality of the data provided (despite many follow ups by the researchers, the managers insisted that they had provided us with all that was available, and that further break downs and clarifications of the cost data were not possible). This common experience (that is, the collection of incomparable data on overhead costs) questions the feasibility and realism of the economic method in relation to costing health services.

Process measures included waiting list times, waiting times in clinics, number of follow up 
attendances, process outcome of consultation, investigations and procedures performed, patient satisfaction with the clinics (using Davies and Ware's Visit Specific Patient Satisfaction Survey questionnaire ${ }^{28}$ ), and staff attitudes towards the clinics. Health status and outcome at six months was measured using the Health Status Questionnaire-12, version 1 (HSQ12.1), a short version of the Short-Form-36, ${ }^{29}$ and other health items; clinical case mix was measured by a specialist's rating of severity, based on the Duke Severity of Illness Scale. ${ }^{30}$

Significant differences are presented by site (outreach/outpatients). All analyses controlled for patient case mix (measured by specialists' ratings of severity of condition; patient reported health status; patient status of new or follow up patient). These analyses are reported where differences between outreach and outpatient clinic attenders were because of differences in case mix. Reference is made to any differences by specialty by site where apparent, although most specialty differences were reduced to non-significance once case mix was controlled for.

Univariate, bivariate, and multivariate analyses were carried out, using frequency distributions, $\chi^{2}$ tests, $t$ tests, Wilcoxon's test, MannWhitney $U$ test, analysis of variance, and logistic regression. Attention has been drawn to statistically significant differences that were achieved at least at the $\mathrm{p}<0.05$ level. Base numbers vary because of some item nonresponse.

\section{RESPONSE RATES}

All patients were approached consecutively as they attended the clinics during the study period and invited to participate. The questionnaires were prepared before the clinic start time, and serial numbers were allocated to patient names in the clinic appointments lists and matched to patient hospital numbers. These were checked after the clinic ended to ensure no one had been missed, and the non-attenders were noted. A total of 1747 outreach and outpatients consented to participate in the study as they attended the clinics, and 109 refused. Their final response rate to the baseline questionnaire was $78 \%$ (1420):OR:82\% (732); OP:74\% (688). The 109 patients who refused to consent to the study when approached in the clinics are included in the non-response figures. Up to four postal reminders were sent. Patients who returned a questionnaire at baseline were sent a six month follow up questionnaire; the response rate was $75 \%$ (1060):OR:75\% (546); OP $75 \%$ (514). Up to four postal reminders were sent at baseline and follow up.

All participating specialists were consultants. All the general practices in the study were fundholding, and two were multi-fundholders. All specialists, GPs and their managers had agreed in principle to complete the study questionnaires before the outreach clinic was included in the study. All but one of the specialists returned their outreach questionnaires (representing 18 outreach clinics-one specialist was a duplicate as he held two of the
19 study outreach clinics); clinical sheets for individual patients were returned by specialists for 672 of the 732 responding outreach patients $(91 \%)$ and for 549 of their 688 responding outpatients $(80 \%) ; 16$ of 19 practice managers responded; 60 of $106(57 \%)$ GPs with the outreach clinics (representing 17 of 19 practices) returned their outreach questionnaires (four of these claimed that the questionnaire should be accepted as representative of all the views of all the doctors in the practice (number of partners $=$ six in each case)); clinical sheets for individual patients were returned by GPs for 434 of their 732 responding outreach patients (59\%) (GPs of outpatients were not included in the study); all 14 trust accountants responded.

\section{Results}

THE CLINICS

The main reason reported by each GP practice (one GP representing each practice provided this information) for establishing the clinic was improvement of accessibility convenience to patients (GP practices: 94\%, 15; specialists: $44 \%, 8$ ), followed by reduction of waiting times for a specialist opinion $(81 \%, 13)$; this was also the most commonly cited reason by specialists $(44 \%, 8)$. The hospital trusts' motivation was financial (to gain income from referrals from outlying practices who did not previously refer patients to that hospital).

The outreach clinics were held, on average, every four weeks, in comparison with weekly outpatient clinics. The specialists reported that the outreach clinics lasted on average 3.03 hours - similar to the 3.50 hours for outpatients. The outreach clinics had between 6 and 28 slots (mean:15.8) and outpatients had between 8 and 43 appointment slots (mean:26) ( $t$ test:4.4; df:16; p<0.0001). Non-attendance figures were collected from records on each site by the researchers. The outreach clinics had lower non-attendance rates than outpatient clinics: $10 \%$ (98):16\% (117) $\left(\chi^{2}: 17.25 ; 1 \mathrm{df}\right.$; $\mathrm{p}<0.0001)$. Outreach patients waited, on average, 5.4 weeks $(95 \%$ CI $5.0,5.7)$ to see the specialist for their first appointment, which was 2.4 weeks less than outpatients who waited, on average, 7.8 weeks ( $t$ test:-6.31; df: 758.91 ; $\mathrm{p}<0.001)$. The outreach group also waited for less time, on average, at the clinic to see the specialist:14.4 minutes, in comparison with 29.9 minutes for outpatients (on average, 15.5 minutes less) ( $t$ test:-11.18; 1023.08 df; $\mathrm{p}<0.001)$.

Forty four per cent (8) of the specialists reported that they conducted the outreach clinic during their NHS time, 28\% (5) conducted the clinic as an extra NHS session $22 \%$ (4) conducted it during private time, and $6 \%$ (1) reported it was conducted during other times. Fifty six per cent (10) of the specialists reported that they took the patient hospital notes to the outreach clinic and $41 \%$ (7) took equipment. Fifty six per cent said that when they referred outreach patients on to the hospital for tests, investigations, procedures or surgery, they were placed on the normal NHS 


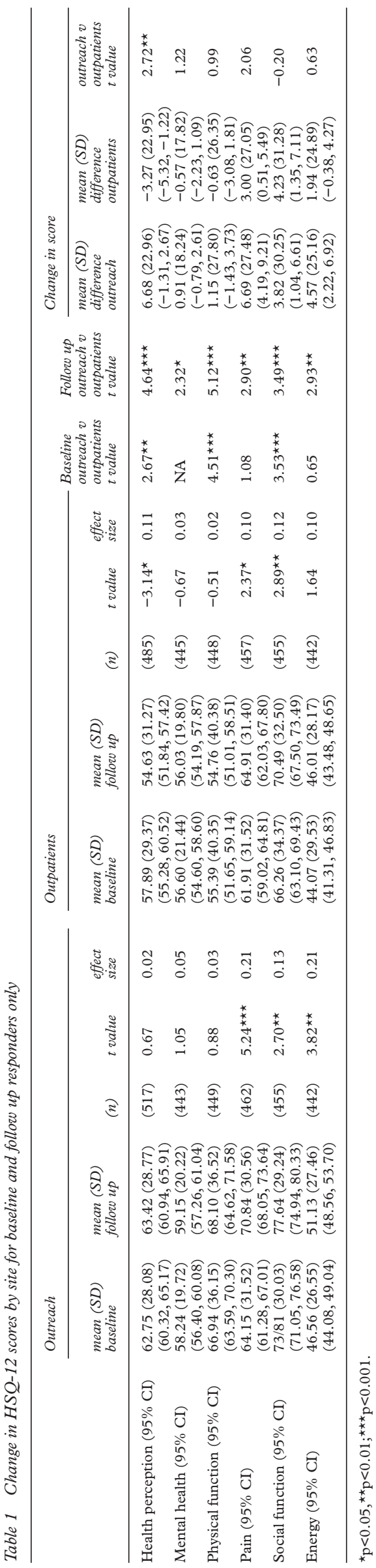

waiting list, and $44 \%$ (8) said they gave them the next available appointment, independently of the NHS waiting list.

PATIENT CHARACTERISTICS, HEALTH STATUS AND HEALTH OUTCOME

There were no differences with patient age, sex or severity of condition (specialist ratings) by site of clinic. Thirty two per cent (414) of all patients were male and $68 \%$ (902) were female. Seven per cent (103) were aged $<16,4 \%(60)$ were $16<25 ; 31 \%$ (425) $25<45 ; 35 \%$ (493) $45<65 ; 23 \%$ (314) were aged $\leqslant 65$. Fifty two per cent (581) of all patients were rated as low severity, $31 \%$ (354) were medium severity, and $17 \%$ (192) were high severity. Outreach patients were more likely than outpatients to be new rather than follow up attenders: $60 \%$ (390), in comparison with $26 \%$ (136) in outpatients $\left(\chi^{2}: 134.5,1 \mathrm{df}, \mathrm{p}<0.00001\right)$. Thirty four per cent (206) of the outreach patients, compared with $26 \%$ (150) of outpatients, had experienced their condition for less than a year $\left(\chi^{2}: 30.4 ; 6 \mathrm{df} ; \mathrm{p}<0.0001\right)$, which is consistent with their greater likelihood of being new rather than follow up patients.

Table 1 shows that, at both baseline and follow up, outreach patients had slightly higher HSQ-12 scores than outpatients, indicating better health status (six of the eight sub-scales are shown in table 1 , the remaining two were dichotomously scored and showed similar trends). Outreach patients were also more likely to have significantly improved health status change scores for health perceptions (their improved follow up scores being a likely effect of their better starting point), although actual point changes were in fact relatively small (table 1).

In relation to the 20 items on other and important areas of life affected, both outreach and outpatients reported significantly fewer limitations by follow up. (1) baseline: outreach mean 5.4 ; outpatients mean 7.0 ; (2) follow up; outreach mean 4.4 , outpatients 5.16 ( $t$ values:outreach:4.86, $\mathrm{p}<0.001$, effect size:0.17; outpatients:2.57, p<0.01, effect size:0.08), although the mean changes were not significantly greater between sites (mean change:outreach -0.91 , outpatients -0.54$)$. The trends were similar for the Rand and the other disease impact items (tables available from author).

At follow up, more of the outreach $(22 \%$, 111) than the outpatients $(13 \%, 66)$ rated the change in their health status as "cleared up altogether", although similar proportions of outreach $(35 \%, 178)$ and outpatients $(37 \%$, 182) said it had "improved" (compared with "not changed", "got worse" or "other" - that is, "too early to say") $\left(\chi^{2}: 23.6 ; 4 \mathrm{df} ; \mathrm{p}<0.0001\right)$.

PATIENT REPORTS OF PROCESS OUTCOMES

Significantly more outreach patients than outpatients were completely discharged (compared with being referred to other services, treatment, surgery or given a follow up appointment) after the sampled clinic attendance:36\% (246):27\% (172) ( $\chi^{2}: 12.8 ; 1$ df; $\mathrm{p}<0.001)$. Similarly, fewer outreach than outpatients reported being given follow up 
Table 2 Patient satisfaction : clinic location and facilities

\begin{tabular}{|c|c|c|}
\hline & Outreach \% (n) & Outpatient \% (n) \\
\hline \multicolumn{3}{|c|}{ Advocacy interpretation facilities $\dagger$} \\
\hline Excellent/very good & $86(19)$ & $75(21)$ \\
\hline Good/fair & $9(2)$ & $18(5)$ \\
\hline Poor & $5(1)$ & $7(2)$ \\
\hline \multicolumn{3}{|l|}{ Convenience of location } \\
\hline Excellent/very good & $81(568)$ & $36(229)^{\star \star \star \star \star \star}$ \\
\hline Good/fair & $18(125)$ & $56(354)$ \\
\hline Poor & $1(6)$ & $8(52)$ \\
\hline \multicolumn{3}{|c|}{ Ease of making/changing appointment } \\
\hline Excellent/very good & $72(143)$ & $58(147)^{\star \star}$ \\
\hline Good/fair & $26(52)$ & $37(94)$ \\
\hline Poor & $2(5)$ & $5(14)$ \\
\hline \multicolumn{3}{|l|}{ Phoning clinic } \\
\hline Excellent/very good & 69 (197) & $49(137)^{\star \star \star \star}$ \\
\hline Good/fair & $28(82)$ & $46(130)$ \\
\hline Poor & $3(8)$ & $5(13)$ \\
\hline \multicolumn{3}{|c|}{ Convenience of appointment day/time } \\
\hline Excellent/very good & $67(466)$ & $48(300)^{\star \star \star \star \star}$ \\
\hline Good/fair & $31(213)$ & $49(310)$ \\
\hline Poor & $2(11)$ & $3(18)$ \\
\hline \multicolumn{3}{|l|}{ Waiting area } \\
\hline Excellent/very good & $64(443)$ & $40(255)^{\star \star \star \star \star}$ \\
\hline Good/fair & $34(236)$ & $53(339)$ \\
\hline Poor & $2(16)$ & $7(45)$ \\
\hline \multicolumn{3}{|c|}{ Patient satisfaction : staff attitudes and waiting times } \\
\hline \multicolumn{3}{|c|}{ Personal manner of specialist } \\
\hline Excellent/very good & $75(517)$ & $67(425)^{\star \star}$ \\
\hline Good/fair & $21(145)$ & $29(186)$ \\
\hline Poor & $4(30)$ & $4(25)$ \\
\hline \multicolumn{3}{|c|}{ Personal manner of reception staff } \\
\hline Excellent/very good & $73(506)$ & $63(405)^{\star \star \star \star \star}$ \\
\hline Good/fair & $26(184)$ & $36(228)$ \\
\hline Poor & $1(7)$ & $1(6)$ \\
\hline \multicolumn{3}{|l|}{ The clinic visit overall } \\
\hline Excellent/very good & $73(501)$ & $55(342)^{\star \star \star \star \star \star}$ \\
\hline Good/fair & $26(177)$ & $42(258)$ \\
\hline Poor & $1(6)$ & $3(18)$ \\
\hline \multicolumn{3}{|c|}{ Thoroughness, carefulness and competence of specialist } \\
\hline Excellent/very good & $71(496)$ & $62(393)^{\star \star \star}$ \\
\hline Good/fair & $27(184)$ & $34(215)$ \\
\hline Poor & $2(14)$ & $4(26)$ \\
\hline \multicolumn{3}{|c|}{ Attention of specialist to what patient said } \\
\hline Excellent/very good & $67(464)$ & $56(354)^{\star \star \star \star \star}$ \\
\hline Good/fair & $30(204)$ & $40(253)$ \\
\hline Poor & $3(24)$ & $4(30)$ \\
\hline \multicolumn{3}{|l|}{ Length of wait at clinic } \\
\hline Excellent/very good & $66(452)$ & $40(256)^{\star \star \star \star \star}$ \\
\hline Good/fair & $29(199)$ & $48(303)$ \\
\hline Poor & $5(38)$ & $12(75)$ \\
\hline \multicolumn{3}{|l|}{ Explanation of treatment } \\
\hline Excellent/very good & $63(430)$ & $52(327)^{\star \star \star \star \star}$ \\
\hline Good/fair & $33(225)$ & $41(259)$ \\
\hline Poor & $4(27)$ & $6(42)$ \\
\hline \multicolumn{3}{|l|}{ Wait for appointment } \\
\hline Excellent/very good & $60(416)$ & $47(295)^{\star \star \star \star}$ \\
\hline Good/fair & $34(237)$ & $43(278)$ \\
\hline Poor & $6(39)$ & $10(61)$ \\
\hline \multicolumn{3}{|l|}{ Time spent with specialist } \\
\hline Excellent/very good & $60(412)$ & $41(263)^{\star \star \star \star \star}$ \\
\hline Good/fair & $37(258)$ & $53(335)$ \\
\hline Poor & $34(21)$ & $6(39)$ \\
\hline Number of respondents $\ddagger$ & $200-699$ & $255-639$ \\
\hline
\end{tabular}

${ }^{\star \star} \mathrm{p}<0.01,{ }^{\star \star \star} \mathrm{p}<0.001,{ }^{\star \star \star \star \star} \mathrm{p}<0.0001,{ }^{\star \star \star \star \star \star} \mathrm{p}<0.00001$

†Advocacy base number: 22 outreach and 28 outpatients (as not all patients needed access to these and they were not required).

$\ddagger$ Base numbers drop to $200-255$ just for all other items that did not apply to all respondents (this was for phoning the clinic and changing appointment, did not apply to respondents who had not attempted to do this).

appointments after the sampled (baseline) consultation: $37 \%(254)$, in comparison with $55 \% \quad$ (346) outpatients $\left(\chi^{2}: 41.6 ; 1 \mathrm{df}\right.$; $\mathrm{p}<0.00001)$. Logistic regression analysis confirmed the independent effect of site over new/ follow up patient status and severity of condition (tables available from the authors).

Taking just the patients who reported that they did not expect to see the specialist in the clinic again $(n=418)$, their use of specialist facilities was not necessarily discontinued: $32 \%$ (78) of these outreach patients and, a similar proportion, $29 \%$ (50) of these outpatients said that, while they had not been given another clinic appointment, they had been referred on by the specialist for surgery or investigations at the hospital. There were no differences between new and follow up attenders. This implies that the true costs of outreach in comparison with outpatient clinics can probably only be truly estimated in a longitudinal study with a resource based costing derived from documented attendances, tests, procedures, surgery, prescriptions and so on, in relation to final outcome (for example, at a two year end point).

\section{PATIENT SATISFACTION}

Outreach patients were more satisfied than outpatients with all but one of the the process and quality issues asked about in the Site Specific Satisfaction battery. In particular, outreach patients were much more likely to be more satisfied than outpatients in relation to the convenience of the location of the clinic. Most of the least differences (although still significant) occurred in relation to the characteristics of the specialist, which would be expected given that it was the same specialist in each paired setting, perhaps only influenced by the very different pressures in each setting (for example, different size clinic lists): explanation of treatment; thoroughness, carefulness and competence of specialist; and the personal manner of the specialist. There was no difference by site and satisfaction with advocacy/interpretation facilities (because of the small numbers the question did not apply to most respondents) (see table 2).

Outreach patients were slightly less likely than outpatients to report at baseline that their treatment could have been improved, although the difference was significant: $15 \%$ (96), 22\% (125) $\left(\chi^{2}: 10.4 ; 2\right.$ df; $\left.\mathrm{p}<0.01\right)$, although by follow up this difference no longer retained significance (22\% (107), 27\% (118) respectively).

Patients' open responses suggesting areas of improvement to the clinic service were coded. The most commonly mentioned area was the need for more information on their condition and the treatment/procedures undertaken: $17 \%$ (14) of outreach and 23\% (23) of outpatients said this (not significantly different). Seventy five per cent (538) of the outreach patients reported that they preferred to see the specialist in their GP's surgery, than in outpatients, compared with $36 \%$ (243) of outpatients (who were asked this hypothetically) $\left(\chi^{2}: 262.9 ; 3 \mathrm{df}\right.$; $\mathrm{p}<0.001)$. Modelling indicated that, although site remained independently significant, a large proportion of these site differences were also explained by the smaller clinic sizes in outreach, in comparison with outpatients (tables available from authors).

DOCTORS' VIEWS ON THE OUTREACH CLINICS

Doctors were asked about the advantages and disadvantages of the outreach clinic. Their attitudes (shown in table 3) coincided with their main reasons for setting up the clinic, which suggests that they felt that their expectations had been met.

The most commonly cited advantage of the outreach clinics by both the GPs and specialists 
Table 3 Specialists' and GPs'views of the advantages and disadvantages of the outreach clinic

\begin{tabular}{|c|c|c|c|c|}
\hline & \multicolumn{2}{|c|}{ Specialists } & \multicolumn{2}{|c|}{$G P s$} \\
\hline & $\%$ & (n) & $\%$ & (n) \\
\hline \multicolumn{5}{|l|}{ Advantages } \\
\hline Improves accessibility/convenience for patients & 100 & $(18)$ & 95 & (54) \\
\hline Reduces waiting times for patients to get appointments & 72 & (13) & 88 & $(50)$ \\
\hline Promotes goodwill & 67 & (12) & 54 & (31) \\
\hline Improves communication between GPs and specialists & 61 & (11) & 74 & $(42)$ \\
\hline Improves access to outpatient clinics for NHS patients & 56 & $(10)$ & 60 & (34) \\
\hline Fewer non-attenders at outreach in comparison with outpatient clinics & 56 & (10) & 67 & (38) \\
\hline To secure fundholder contracts for hospital & 56 & $(10)$ & 7 & $(4)$ \\
\hline Improves specialists' job satisfaction & 22 & (4) & - & NÁ \\
\hline Personal financial benefits for specialist & 22 & (4) & 5 & (3) \\
\hline Broadening of GPs' skills & 11 & (2) & 44 & $(25)$ \\
\hline Improves access to private referrals & 6 & (1) & 2 & (1) \\
\hline Having hospital notes & 6 & (1) & - & $\mathrm{NA}$ \\
\hline Improves GPs' job satisfaction & - & NA & 49 & (28) \\
\hline Cheaper service than outpatients & - & NA & 44 & $(25)$ \\
\hline Other advantages & 11 & (2) & 4 & (2) \\
\hline No advantages & - & $(0)$ & 2 & (1) \\
\hline \multicolumn{5}{|l|}{ Disadvantages } \\
\hline Reduces specialist time in hospital (NHS) & 72 & (13) & 22 & (12) \\
\hline Travelling time for specialist & 67 & (12) & - & $\mathrm{NA}$ \\
\hline Reduces specialists' time for other work & 50 & (9) & - & NA \\
\hline Inflexible/infrequent follow up intervals & 39 & (7) & 93 & (51) \\
\hline Specialist having to bring hospital notes & 39 & (7) & - & NA \\
\hline Reduces training time for junior hospital doctors & 39 & (7) & - & NA \\
\hline Fewer patients seen per clinic than in outpatients & 28 & (5) & 11 & $(6)$ \\
\hline Not having hospital notes & 22 & (4) & 9 & (5) \\
\hline Inadequate administrative back up in GPs' surgeries & 11 & (2) & - & NA \\
\hline Increase in GPs' administrative costs/time & - & NA & 43 & (25) \\
\hline Less time for GPs' other work & - & NA & 6 & (3) \\
\hline Other disadvantages & 11 & $(2)$ & 4 & (2) \\
\hline No disadvantages & - & $(0)$ & 27 & (15) \\
\hline Number of respondents & & 18 & & $55-57$ \\
\hline
\end{tabular}

was the improvement of patient access to the specialist and convenience to the patient, followed by reduced waiting time for appointments. Other commonly cited advantages were improved goodwill, and also communication between GPs and specialists.

The most commonly cited disadvantage of the outreach clinic was said by GPs to be the inflexible or infrequent follow up intervals (that is, if the specialist attends just once a month or every six weeks then follow up consultations are delayed until then). The next most common disadvantage they mentioned was the increase in the GP administrative time and costs. The most common disadvantage cited by specialists was the reduction in the specialist time in hospital (NHS), followed by their travelling time.

Ninety six per cent (53) of the GPs and $88 \%$ (15) of the specialists reported that they felt that the outreach clinic was "worthwhile"; there were no differences by specialty of the clinic. Thirty nine per cent (7) of the specialists were planning other outreach clinics.

Fifty eight per cent (11) of the 19 specialists held education/training sessions (called "teach and treat") with the GPs, although just 26\% (5) reported having regular contact with the GPs at the outreach clinics. Both GPs and specialists reported a change in referral patterns to the specialist since the establishment of the outreach clinic: $46 \%$ (26) of the GPs and 33\% (6) of the specialists reported a decline in numbers of referrals, although 13\% (7) of GPs and 6\% (1) of specialists reported an increase; $5 \%$ (3) of GPs and $17 \%$ (3) of specialists reported a different type of referral and the remainder said there had been no change $(32 \%, 18 ; 33 \%$ (6) respectively) or they did not know (4\% (2), $11 \%$ (2) respectively). Data from the practice managers (controlling for list size over time) confirmed a reduction in referrals by a third. Twenty two per cent (4) of the specialists reported that the appropriateness of the GP referrals had changed (that is, more appropriate) as a result of the outreach clinic, $61 \%$ (11) said they had not and the remainder said it was too early to tell or they were uncertain.

costs

The mean total cost to the patient (travel, cost of care for dependents and opportunity costs) was $£ 9.97$ in outpatients and $£ 4.55$ in outreach, a difference of $-£ 5.42$ ( $t$ value:12.70. $\mathrm{p}<0.001$ ). This was attributable largely to differences in the distance travelled, and associated costs. Outreach patients travelled shorter distances to and from the clinics than outpatients at $7.0(95 \% \mathrm{CI}$ $6.4,7.7)$ miles in comparison with 19.0 (95\% CI $16.3,21.7$ ) miles for outpatients (on average 12 miles less (95\%CI -14.8, -9.3) ( $t$ test -8.40 ; $\mathrm{p}<0.001)$.

The mean total NHS treatment costs (prescribed medication for the study condition, investigations and interventions (treatment, surgery) per patient were significantly higher in outreach than outpatients: $£ 163.73: £ 109.20$ (95\%CI 127.69, 199.77; 79.86, 138.54), $t$ value $2.30, \mathrm{p}<0.05$.

The mean difference was $£ 54.53$ (95\%CI $8.09,100.97)$. The higher overall treatment costs in outreach only partly reflected the greater number of new attenders in the outreach clinics. The mean total treatment costs for new attenders were still higher in outreach - at over $£ 50$ per patient greater in outreach than in outpatients. In all specialties, the mean medical and nursing staffing costs in outreach were significantly higher at $£ 2.73$ (95\%CI 2.17, 3.30) per patient more than 
outpatients ( $£ 13.80$ in outreach and $£ 11.07$ in outpatients $(t$ value $9.46, \mathrm{p}<0.0001)$ ).

The mean opportunity cost for outreach (the opportunity cost of staff travel times and travel costs applied only to the outreach clinics) was $£ 1.72(95 \%$ CI $1.62,1.82)$ per outreach patient. Their time should not strictly be included for the calculation of opportunity cost as they were engaged in NHS work. However, for information, the mean opportunity cost of the specialist clinic time, including travelling time (although excluding travel costs) was: $£ 137$ (95\%CI 128, 145). The mean of each of these costs to outreach per patient was $£ 15.52(£ 13.80+£ 1.72)$, in comparison with $£ 11.07(95 \%$ CI $10.72,11.42)$ in outpatients (a mean difference of $£ 4.45$ per patient ( $t$ test 16.45, df 1297.18, p<0.001). The overhead costs are not given here as the practice and trust figures were not standardisable (tables available from authors).

Further analyses, using analysis of variance, of the outreach clinic costs showed that the smallest outreach clinics (10 or fewer patients booked) cost almost twice as much to staff as the largest clinics (20 or more patients booked). This was because of the fixed costs of travelling to and from the clinic, and setting it up, were distributed across a smaller number of patients (tables available from the authors).

\section{Discussion}

In contrast with countries without a strong primary care infrastructure, people in the UK have good access to primary care physicians (GPs). However, apart from containing costs, one of the main health care problems in the UK is speeding up access to specialist services in the secondary care sector. Policy makers in the UK have driven organisational changes in the primary care sector in the light of these issues. This is the first large study of the costs and benefits of one of the service developments to arise largely from GP fundholding practices. While specialist outreach clinics are not unique to fundholding practices, they were relatively rare before, and fundholding led to a large increase in their numbers.

The study reported here showed that, while patient satisfaction levels in outreach were superior to outpatient clinics, their access to specialist care was greater than that of outpatients, and they were more likely to be discharged, the health benefits were little greater than in outpatients. Like the evaluation of dermatology and orthopaedics outreach clinics $^{25}{ }^{26}$ the study reported here found that the NHS costs were significantly higher in outreach than outpatient clinics. Both studies also found that communication between GPs and specialists was limited. Unlike the former evaluation, which reported that dermatology outreach patients were less enthusiastic about seeing the specialist in the GP surgery, compared with in hospital, the majority of outreach patients, across all specialties, in the study reported here were positive about the outreach clinic. They were far more satisfied than outpatients about the processes of the clinic. Both studies, however, reached the same
KEY POINTS

- Outreach patients were more satisfied than outpatients in relation to the processes of their care.

- Patient access to specialist care was better in outreach than in outpatient clinics.

- Efficiency of care was greater in outreach than outpatient clinics, with outreach patients being more likely than outpatients to be discharged.

- The health status of the outreach sample had improved slightly more than that of the outpatients.

- While patients' own costs were lower, NHS staffing and treatment costs were more expensive per patient in outreach than outpatient clinics.

conclusion overall-that if the increasing demand for outreach clinics is met, the workload of the specialist in hospital could be adversely affected. In conclusion, while the process of care was of higher quality in outreach than in outpatients, and efficiency was also greater in the outreach setting, this was at a substantially higher cost, and the effect on patient health outcomes was small. The policy implication, which is also of international relevance, is that, in the short-term, the costs of health care are more likely to be contained by retaining the current hospital outpatient system alone, rather than supplementing this with specialist outreach services to individual practices where fewer patients can be seen, investigative technology is often unavailable, and with consequences for costs. However, the real costs of outreach in comparison with outpatients clinics can probably only be truly estimated in a longitudinal study with a resource based costing model derived from documented patient attendances and treatment costs over time in relation to longer term outcome (for example, at a two year end point). In addition, the greater efficiency of outreach in comparison with outpatient clinics also needs to be measured over time. The question remains: Is the one third reduction in direct referrals to outpatient departments from outreach practices, the lower non-attendance rates in outreach, the increase in appropriate outpatient referrals from outreach practices (reported by over a fifth of the specialists), together with the higher patient discharge rate in outreach, maintained, or even accelerated, over time? If outreach results in an increasing number of more appropriate referrals to specialists over time then their increased costs may be judged to be worthwhile.

Funding: NHS Executive (grant:PSI 11-27) Conflicts of interest: none.

We thank Margaret Hall, Pauline Marsh and Brian Tucker for assistance with coding and data entry; Lee Marriott for administrative assistance; Judith Redfern, Joy Windsor and members of the study's advisory group for advice and support,
particularly Ms Merev Dover, Dr Alan Glanz, Dr Anita particularly Ms Merev Dover, Dr Alan Glanz, Dr Anita
Houghton, Dr Dipak Kalra, Professor Lesley Southgate and Dr Houghton, Dr Dipak Kalra, Professor Lesley Southgate and Dr
Janet Wisely. We also thank our colleagues at the National PriJanet Wisely. We also thank our colleagues at the National Priof Manchester for their willing collaboration on questionnaire 
design and the costing methodology, in particular Ms Mary Black, Mr Toby Gosden, Dr Brenda Leese, Ms Nicola Mead, and Professor David Wilkin. Finally, we are grateful to the GPs, specialists, patients and managers who gave their time so willingly to participate in the study, and to the NHS Executive for funding it (grant:PSI 11-27).

The views expressed do not necessarily represent those of the advisors or the funding body.

1 Honigsbaum F, Calltorp J, Ham C, et al. Priority setting processes for health care. Oxford: Radcliffe Medical Press, 1995. 2 Bowling A. Health care rationing:the public's debate. $B M \mathcal{F}$ 1997;312:670-4.

3 Mechanic D. Failure of health care reform in the USA. Fournal of Health Services Research Policy 1995;1 (pre-launch issue): $4-9$

4 Coulter A. Evaluating general practice fundholding in the United Kingdom. Eur 尹 Public Health 1995a;5:233-9.

5 Sanders D, Coulter A, McPherson K. Variations in hospital admission rates: a review of the literature. London: King's Fund, 1989.

6 Starfield B. Is primary care essential? Lancet 1994;344: 1129-33.

7 Light DW. Homo Economicus:escaping the traps of managed competition. Eur 7 Public Health 1995;5:145-54.

8 Enthoven AC. Reply on managed competition. Eur f Public Health 1995;5:155

9 Department of Health. The NHS and Community Care Act. London: HMSO, 1991.

10 Department of Health. Practice budgets for general medical practitioners. Working paper no 3. London: Her Majesty's Stationary Office, 1989 a

11 Department of Health. Funding general practice:the programme for the introduction of GP budgets. London: Her Majesty's Stationary Office, 1989b.

12 Department of Health. The new GP contract. London: Her Majesty's Stationary Office, 1990.

13 McKee M. What can we learn from the British fundholding experience? Eur F Public Health 1995;5:213-32.

14 Coulter A. Shifting the balance from secondary to primary care. BMF 1995;311:1447-8.

15 Department of Health. The new NHS. Cm 3807. London: Stationary Office, 1997.

16 Groenewegen PP, Calnan M. Changes in the control of health care systems in Europe. Eur F Public Health 1995;5: $240-4$.

17 Ham C, Robinson R, Benezeval M. Health check:health policy in an international perspective. London: King's Fund Institute, 1990
18 McKee M, Bobal M, Kalina K, et al. Health sector reform in the Czech republic, Hungary and Romania. Croatian Med $\mathcal{F}$ 994;35:238-44.

19 Rosenbaum S, Hawkins DR, Rosenbaum E, et al. State unding of comprehensive primary medical care service programs for medically underserved populations. Am $\mathcal{F}$ Public Health 1998;88:357-63.

20 Bailey JJ, Black ME, Wilkin D. Specialist outreach clinics in general practice. BMF 1994;308:1083-6.

21 Shapiro J, Perrett K. Introduction. In: Roland M, Shapiro J, eds. Specialist outreach clinics in general practice. National Primary Care Research and Development Centre Series. Abingdon: Radcliffe Medical Press, 1998.

22 Bowling A, Stramer K, Dickinson E, et al. Evaluation of specialists' outreach clinics in general practice in England: process and acceptability to patients, specialists, and general practitioners. If Epidemiol Community Health 1997;51:52-61

23 Walshe K, Shapiro J. Wolverhampton.In: Roland M, Shapiro J, eds. Specialist outreach clinics in general practice. National Primary Care Research and Development Centre Series. Abingdon: Radcliffe Medical Press, 1998.

24 Gillam SJ, Ball M, Prasad M, et al. Investigation of benefits and costs of an ophthalmic outreach clinic in general practice. Br F Gen Pract 1995;45:649-52.

25 Black M, Leese B, Gosden T, et al. Specialist outreach clinics in general practice:what do they offer? $\mathrm{Br} f \mathrm{~F}$ Gen Pract 1997;47:558-61.

26 Gosden T, Black M, Mead N, et al. The efficiency of specialist outreach clinics in general practice:is further evaluation needed? Fournal of Health Services Research Policy 1997;2:174-9.

27 Mead N, Gosden T, Roland M. Conclusions and key issues for the future. In: Roland M, Shapiro J, eds. Specialist outreach clinics in general practice. National Primary Care Research and Development Centre Series. Abingdon: Radcliffe Medical Press, 1998.

28 Davies AR, Ware JE. GHAA's Consumer Satisfaction Survey and Manual. Washington: Group Health Association of America, 1991.

29 Radosevich D, Pruitt M. Twelve-item health status questionnaire. HSO-12 version 2.0. Bloomington, $\mathrm{MN}$ : Health Outcomes Institute, 1995.

30 Parkerson GR, Broadhead WE, Tse C-K, J. The Duke Severity of illness Checklist (DUSOI) for measurement of severity and co-morbidity. F Clin Epidemiol 1993;46:379-93. 